\title{
Modification of titania nanoparticles for photocatalytic antibacterial activity via a colloidal route with glycine and subsequent annealing
}

\author{
Mamoru Senna ${ }^{\text {a) }}$ \\ Laboratoire de Technologie des Poudres, EPFL, CH-1015 Lausanne, Switzerland; and Faculty of Science \\ and Technology, Keio University, J-223-8522 Yokohama, Japan \\ Nicholas Myers \\ Laboratoire de Technologie des Poudres, EPFL, CH-1015 Lausanne, Switzerland \\ Anne Aimable \\ Ecole Nationale Supérieure de Céramique Industrielle, Limoges 87068, France \\ Vincent Laporte \\ Interdisciplinary Centre for Electron Microscopy, EPFL, CH-1015 Lausanne, Switzerland \\ Cesar Pulgarin and Oualid Baghriche \\ Groupe de Procédés Avancés d'Oxydation, EPFL, CH-1015 Lausanne, Switzerland \\ Paul Bowen \\ Laboratoire de Technologie des Poudres, EPFL, CH-1015 Lausanne, Switzerland
}

(Received 7 May 2012; accepted 28 June 2012)

\begin{abstract}
Changes in the colloid-chemical and photocatalytic properties of titania nanoparticles by attrition milling in the presence of glycine (Gly) and subsequent heat treatment were examined. By milling at $1500 \mathrm{rpm}$ for $6 \mathrm{~h}$, the average particle size was decreased from 123 to $85 \mathrm{~nm}$, with simultaneous decrease in the specific surface area from 35.1 to $23.5 \mathrm{~m}^{2} / \mathrm{g}$. Interfacial reactions between titania and Gly were confirmed by Fourier transform infrared spectroscopy, from the blue shift of the $\mathrm{COO}^{-}$related vibrational bands by $25 \mathrm{~cm}^{-1}$, relative to the same band from the pristine Gly. The bimodal N1s x-ray photoelectron spectroscopy peak similar to that from the reported titania-amino acid complex is another indication of the complex formation with the participation of nitrogen. When the dispersion was dried and calcined at $500{ }^{\circ} \mathrm{C}$ in air, the powder exhibited pale yellow color. Diffuse reflectance spectroscopy showed significant visible light absorption, suggesting nitrogen incorporation into titania. The fired product showed high photocatalytic antibacterial activity by irradiation of blue light centered at around $440 \mathrm{~nm}$, using Escherichia coli as a specimen of bacterial species. Thus, the present Gly-modified titania nanoparticles could be used for eliminating indoor bacteria under soft blue illumination. The series of interfacial chemical processes involved are also discussed.
\end{abstract}

\section{INTRODUCTION}

Most of the functional oxide nanoparticles used to fabricate final products in the forms of sintered bodies, thick or thin films, are processed via a colloidal state, where a good dispersion is of primary importance. ${ }^{1-4}$ It is widely accepted that appropriate anion exchange of the oxide nanoparticles brings about increased functionality, by changing the electronic states of the oxides. ${ }^{5-7}$ Numerous attempts were made, for instance, to incorporate nitrogen, sulfur, and/or fluorine into titania nanoparticles, for making them responsive to visible light. ${ }^{8-14}$ Out of a number of such functionalization techniques, dry processing such as comilling oxide particles with appropriate anion sources in

\footnotetext{
a) Address all correspondence to this author.

e-mail: senna@applc.keio.ac.jp

DOI: $10.1557 / \mathrm{jmr} .2012 .257$
}

a solid state is recognized to be beneficial, ${ }^{15-17}$ while a number of colloid-chemical processing of titania fine particles for the similar purposes are documented as well. ${ }^{18-20}$

Comilling of titania nanoparticles with polytetrafluoroethylene (PTFE) in air, for instance, brings about fluorinedoped $\mathrm{TiO}_{2}$ nanoparticles, as we reported recently. ${ }^{21}$ The associated reaction processes, i.e., oxidative decomposition of PTFE, extraction of oxygen ion from the substrate titania, and transfer of fluorine from the partially decomposed PTFE, are the consequences of serial mechanochemical reactions. While these dry comilling processes look promising, they are often accompanied by severe agglomeration of the particles.

A wet milling process, on the other hand, is almost always performed for the purpose of better dispersion. It is generally believed, however, that mechanochemical effects may be lower in extent, due to the presence of 
a liquid phase. With an appropriate liquid phase, however, we could induce a dissolution-reprecipitation phenomenon, which is entirely missing in the dry processing route. Indium-tin oxide (ITO) is a source of transparent conducting thin films, whose demands are ever increasing for displays, photovoltaics and touch panels. ${ }^{22,23}$ For obtaining a well-sintered material, serving as a target of subsequent sputtering, we need highly sinterable ITO sources. Wet milling of indium oxide powders in an aqueous solution of stannic chloride $\left(\mathrm{SnCl}_{4}\right)$ results in the partial dissolution of indium oxide $\left(\operatorname{In}_{2} \mathrm{O}_{3}\right)$, formation of the complex hydrated ionic species in an aqueous phase and their deposition onto the surface of $\operatorname{In}_{2} \mathrm{O}_{3}$ particles. ${ }^{24}$

By the same token, wet milling of titania in a reactive medium containing appropriate anion source may enable surface modification of titania, while avoiding serious agglomeration. The purpose of the present study is to prepare photocatalytically active titania nanoparticles, by dispersing them in a slightly acidic aqueous solution of glycine, serving as a nitrogen source, attrition milling and subsequent drying and annealing. Photocatalytic properties were examined in terms of antibacterial activity using Escherichia coli as a specimen of bacterial species.

\section{EXPERIMENTAL}

\section{A. Samples}

As a source of $\mathrm{TiO}_{2}$ nanoparticles, we chose P-25 (Evonik Degussa, Essen, Germany, average primary particle size $40 \mathrm{~nm}$ ), as purchased. Glycine (henceforth Gly, SigmaAldrich, St. Louis, MO) was used without any further purification. A $16.7 \mathrm{wt} \%$ aqueous solution of Gly was prepared by dissolving $20 \mathrm{~g}$ Gly in $100 \mathrm{~mL} 0.1 \mathrm{~N}$ nitric acid $\left(\mathrm{HNO}_{3}\right)$. The solution $\mathrm{pH}$ was 3.4. Attrition milling was performed on the suspension comprising $20 \mathrm{~g}$ of P-25 and $30 \mathrm{~g}$ of the above-mentioned Gly solution using Netzsch PE075 mill (Netzsch, Selb, Germany), with yttrium-stabilized zirconia beads $(2.5 \mathrm{~mm}) 180 \mathrm{~g}$, at $1500 \mathrm{rpm}$ for $6 \mathrm{~h}$ (henceforth, sample AT4). The attrition-milled sample was dried at $76{ }^{\circ} \mathrm{C}$ for $24 \mathrm{~h}$ and heated in air at $10^{\circ} \mathrm{C} / \mathrm{min}$ up to $500{ }^{\circ} \mathrm{C}$, held for $1 \mathrm{~h}$, and furnace-cooled (samples AT4C1 (1) and AT4C1 (2), with the same P-25 from different lots).

\section{B. Characterization}

Granulometrical analyses were performed for the particle size distribution with CPS Disk Centrifuge, DC24000 (CPS Instruments, Oosterhout, Netherlands), and for the nitrogen-specific surface area using the method of Brunauer, Emmett and Teller (BET model) with a Gemini 2375 (Micromeritics Instrument, Norcross, GA). We also evaluated colloid-chemical properties, i.e., zeta potential for the as-prepared suspension by Zetapals, BI9000AT (Brookhaven Instruments, Holtsville, NY), and viscometry by Haake Rheostress, RS 100 with a cone-cylinder set up at $25{ }^{\circ} \mathrm{C}$. Solid state properties were determined by $\mathrm{x}$-ray diffractometry (XRD; Philips X Pert, Eindhoven, Netherlands), thermogravimetric analysis (TGA; TGA/SDTA851e, Mettler Toledo, Columbus, OH), diffuse reflectance spectroscopy (DRS) [Lambda 900, Perkin Elmer, Waltham, MA, ultraviolet, visible, near-infrared (UV-VIS-NIR) spectrometer], x-ray photoelectron spectroscopy (XPS; Axis Ultra, Kratos Analytical, Manchester, UK), and Fourier transform infrared spectroscopy (FTIR; Nicolet 5 ZDX, Thermo Fisher Scientific, Waltham, MA).

Photocatalytic antibacterial activity was evaluated using Escherichia coli (E. coli K12) as a specimen of bacterial species. This was obtained from the Deutsche Sammlung von Mikroorganismen und Zellkulturen GmbH (DSMZ) ATCC23716, Braunschweig, Germany. The bacteria was inoculated in $5 \mathrm{~mL}$ of Luria Bertani solution and grown for $8 \mathrm{~h}$ at $37^{\circ} \mathrm{C}$ under constant agitation to maintain aerobic conditions. Aliquots of the culture were inoculated into a fresh medium and incubated aerobically at $37^{\circ} \mathrm{C}$ for $15 \mathrm{~h}$.

Bacterial growth was monitored by optical density at $600 \mathrm{~nm}$. At the stationary growth phase, bacteria cells were collected by centrifugation at $5000 \mathrm{rpm}$ for $15 \mathrm{~min}$ at $4{ }^{\circ} \mathrm{C}$. The bacterial pellets were washed three times and resuspended in a saline solution comprising $0.75 \%$ sodium chloride $(\mathrm{NaCl})$ and $0.08 \%$ potassium chloride $(\mathrm{KCl})$. Finally, cell suspensions were diluted with the saline solution to allow the storage of the bacteria without osmotic stress, ${ }^{25}$ and to the required cell density [corresponding to $1.0 \times 10^{6}$ to $3.0 \times 10^{6}$ colony forming units per milliliter, $(\mathrm{CFU} / \mathrm{mL})]$. Samples were taken each $30 \mathrm{~min}$ until $4.5 \mathrm{~h}$ of illumination. Serial dilutions were made in the saline solution. A $100 \mu \mathrm{L}$ of each dilution was spread on the nutrient agar plates, which were incubated for $37^{\circ} \mathrm{C}$ for $24 \mathrm{~h}$ before counting the $\mathrm{CFU}$.

A Pyrex glass bottle of $50 \mathrm{~mL}$ was used as a batch reactor. The catalysts concentration was kept constant at $1 \mathrm{~g} / \mathrm{L}$. The volume of the bacteria solution was $40 \mathrm{~mL}$. The irradiation experiments were performed at room temperature, $25{ }^{\circ} \mathrm{C}$, which increased up to $31{ }^{\circ} \mathrm{C}$ during irradiation. All experiments were repeated three times.

\section{EXPERIMENTAL RESULTS}

\section{A. Granulometry of powders}

Particle size distribution of the original P-25, gave a single mode at $123 \mathrm{~nm}$, which shifted toward smaller size, $85 \mathrm{~nm}$, after attrition milling, as shown in Fig. 1. The particle size reduction was also recognized by the scanning electron micrographs shown in Fig. 2, where the AT4 powder suggests a slightly lower degree of agglomeration. In contrast to the expectation from the geometry, the BETspecific surface area, the weight-based value, $S_{\mathrm{w}}$, also decreased after attrition milling, as shown in Table I. 

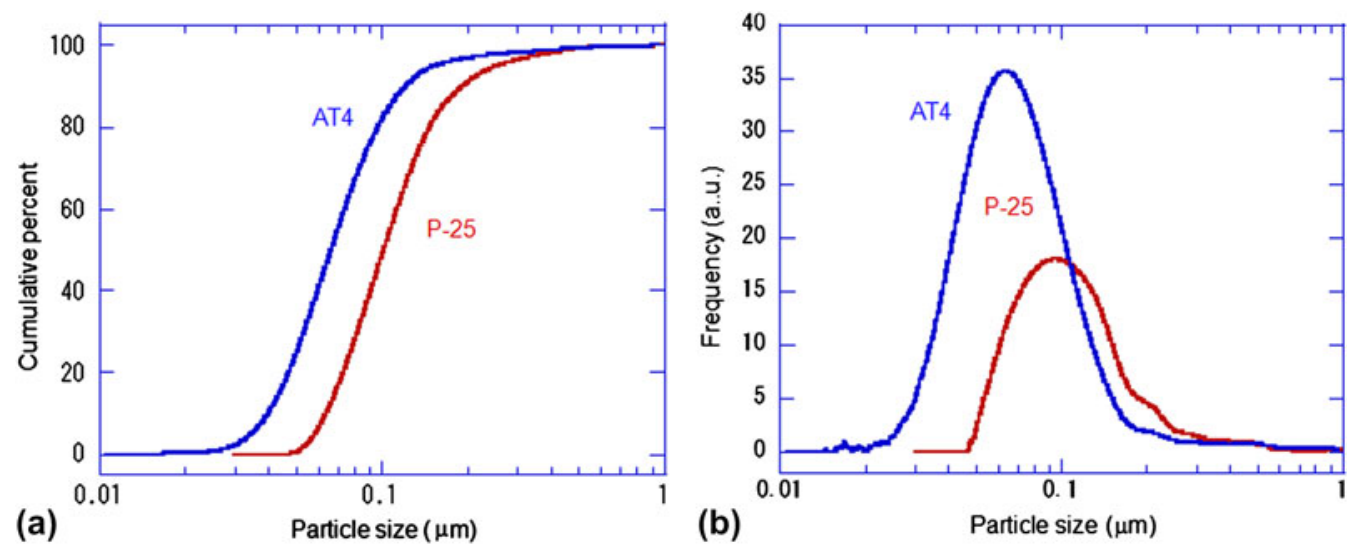

FIG. 1. Particle size distribution profiles. (a) cumulative, (b) histogram.
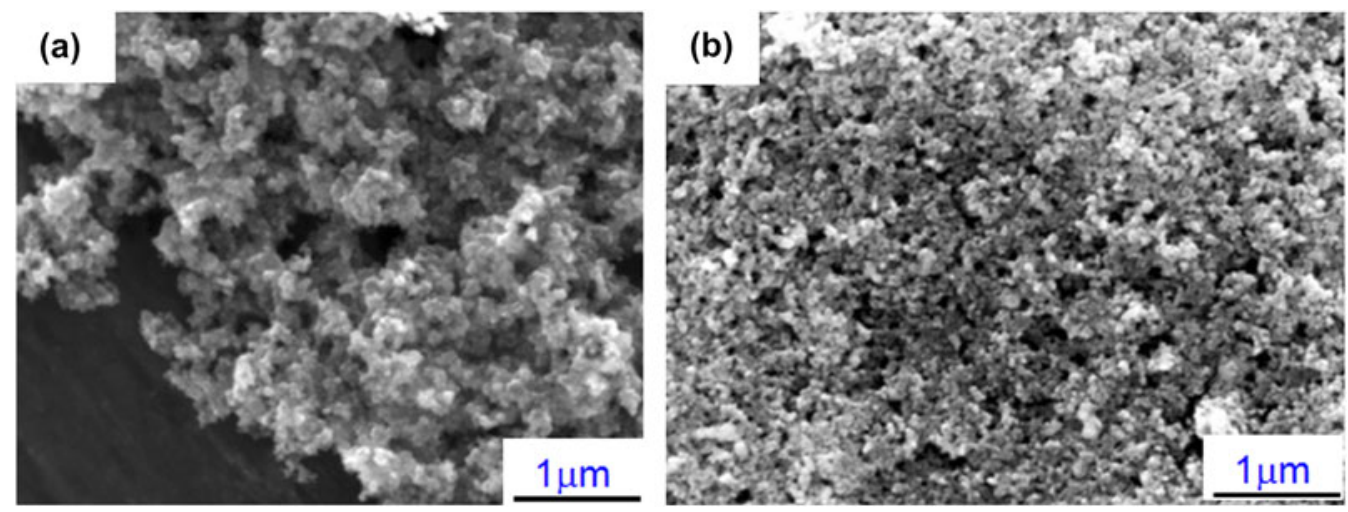

FIG. 2. Scanning electron micrographs. (a) Starting mixture before attrition milling, (b) after attrition milling (AT4).

TABLE I. Summary of granulometrical results.

\begin{tabular}{lccc}
\hline \hline Sample & $D_{\mathrm{w} 50}(\mathrm{~nm})$ & $S_{\mathrm{w}}\left(\mathrm{m}^{2} / \mathrm{g}\right)$ & Relative dispersion \\
\hline P-25 & 123 & 35.1 & 1 \\
AT4 & 85 & 23.5 & 0.46 \\
\hline \hline
\end{tabular}

The relative dispersion of AT4 was estimated by dividing the weight-based average particle size, $D_{\mathrm{w} 50}$, by the reciprocal of $S_{\mathrm{w}}$ and normalized by the corresponding value of the pristine P-25. The value became 0.46 , after attrition milling. This is an indication of agglomeration after attrition milling. However, the agglomeration was weak enough to be destroyed and redispersed by ultrasonication, demonstrated by the particle size distribution. The Gly absorption on the attrition milled powder also explains the decrease in the $S_{\mathrm{w}}$. Gly could block access of nitrogen to pores within the agglomerates as the powder was only treated at $200{ }^{\circ} \mathrm{C}$ before measurement of the nitrogen isotherm, below the temperatures for full decomposition of the adsorbed Gly.

\section{B. Colloid-chemical and rheological properties}

Table II summarizes the colloid-chemical properties before and after attrition milling. Decrease in the zeta
TABLE II. Summary of colloidal properties.

\begin{tabular}{lcccc}
\hline \hline & & & \multicolumn{2}{c}{$\begin{array}{c}\text { Apparent } \\
\text { viscosity (mPa s) }\end{array}$} \\
\cline { 3 - 5 } Disperse system & $\mathrm{pH}$ & $\begin{array}{c}\text { Zeta } \\
\text { potential (mV) }\end{array}$ & At $300 \mathrm{~s}^{-1}$ & At $600 \mathrm{~s}^{-1}$ \\
\hline $\begin{array}{c}\text { P-25 before attrition } \\
\text { milling }\end{array}$ & 3.4 & 33.6 & 32 & 24 \\
$\begin{array}{c}\text { P-25 after attrition } \\
\text { milling }\end{array}$ & 3.4 & 28.8 & 3 & 4 \\
$\begin{array}{c}\text { P-25 + Gly before } \\
\text { attrition milling }\end{array}$ & 3.5 & 26 & 42 & 27 \\
$\begin{array}{c}\text { P-25 + Gly before } \\
\text { attrition milling (AT4) }\end{array}$ & 3.5 & 12 & 7 & 6 \\
\hline \hline
\end{tabular}

potential was observed after attrition milling and addition of Gly. When attrition milling was performed in the presence of Gly, the reduction of the zeta potential was most appreciable, again indicating surface modification in the presence of Gly.

Apparent viscosity was decreased with increasing shear rate, indicating the shear thinning behavior for the nonmilled suspensions. Significant decrease in the apparent viscosity by attrition milling was also observed. These are typical rheological behaviors of the disperse systems containing agglomerates. ${ }^{26}$ Irreversible and significant decrease 
in the apparent viscosity by attrition milling indicates that the strong aggregates were present in the initial titania particles, which are significantly destroyed by attrition milling. A slight increase in the apparent viscosity in the presence of Gly, both before and after attrition milling, is an indication of chemical interaction of Gly with titania particles, reducing the degree of dispersion.

\section{Change in the chemical properties by attrition milling}

FTIR spectra shown in Fig. 3(a) exhibit primarily the disappearance of the absorption peaks of pristine Gly below $800 \mathrm{~cm}^{-1}$ for AT4, due to attrition milling. A closer observation reveals a significant blue shift by up to 25 wave number for the absorption bands between 1300 and $1500 \mathrm{~cm}^{-1}$, ascribed to the $\mathrm{COO}^{-}$stretching, ${ }^{27,28}$ as shown in Fig. 3(b).

When we observe N1s XPS peaks for the same samples, shifts toward lower binding energy was recognized as shown in Fig. 4(a). A closer look at the N1s signal for the composite (AT4), we notice that the peak could be separated into two components, i.e., with peaks at 399.8 and $401.5 \mathrm{eV}$, as shown in Fig. 4(b). This will be further discussed in Sec. IV. We note that the same tendency was observed for the system $\mathrm{TiO}_{2}-\mathrm{L}$-serine. ${ }^{29}$

\section{Changes upon heating}

Upon heating, the decomposition behaviors were also significantly different between the pristine Gly and G attrition milled with titania, as shown by the differential thermogravimetrical (DTG) profiles shown in Fig. 5. Both the initiation and termination temperatures of the weight loss, i.e., the thermal decomposition, were shifted toward lower temperatures for the organic part of the attritionmilled composite. In the latter case, the fractional decomposition steps were more widely spread. This is another indication of significant chemical interaction of Gly with titania, i.e., beyond the state of simple adsorption.

Figure 6 shows the diffuse reflectance spectra of the parent P-25 powder and two powders after comilling and thermal treatment at $500{ }^{\circ} \mathrm{C}$ for $1 \mathrm{~h}$ in air. There is significant enhancement in the light absorption in the visible region between 300 and $400 \mathrm{~nm}$ for the comilled and heated powders compared with the parent P25. Two samples, AT4C1 (1) and AT4C1 (2), are those of the same treatment from the different starting batches (lots) of P25. They behaved quite similarly, showing good reproducibility of the phenomenon.

\section{E. Photocatalytic activities}

Figure 7(a) shows the activity under green light irradiation. There is small, almost negligible activity for the parent P25 and AT4C1 and C2 samples. This is not unexpected from the absorption data in Fig. 6, where none of the powder absorbs the photon energy in this energy region.
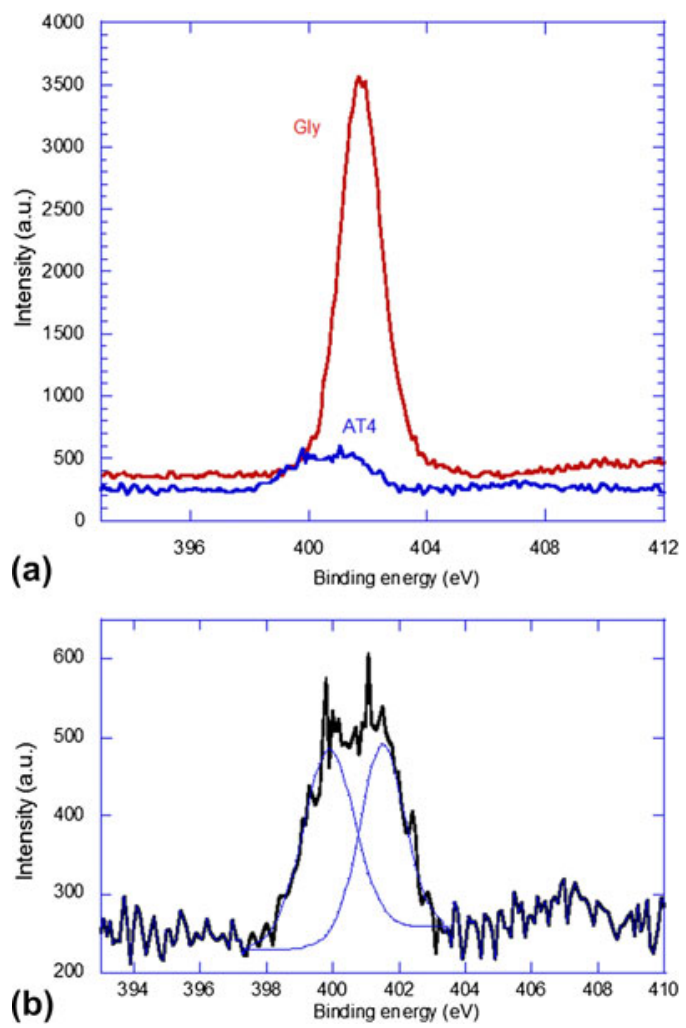

FIG. 4. N1s XPS profiles. (a) Gly and AT4, (b) AT4 with peak deconvolution.
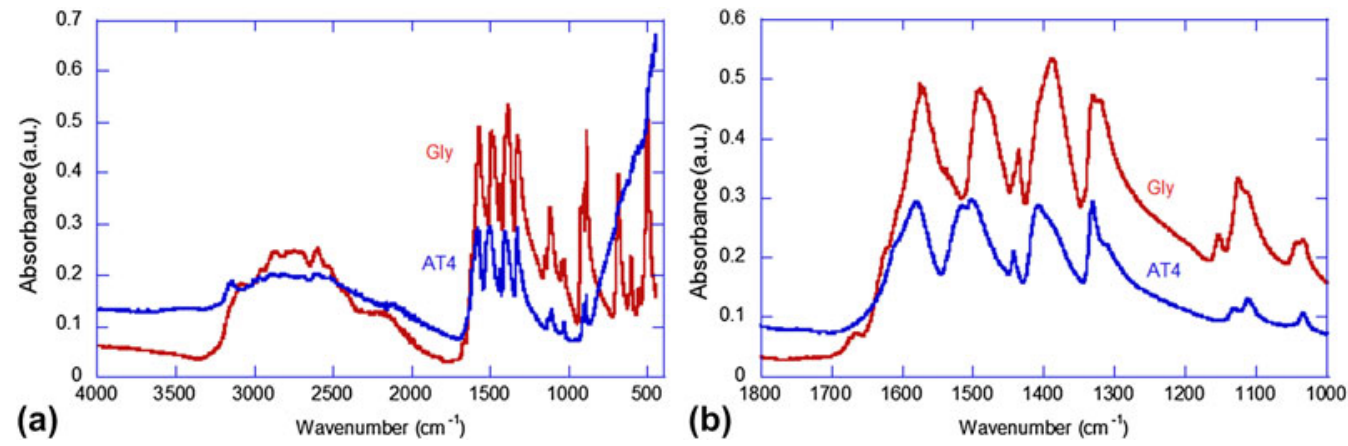

FIG. 3. FTIR spectra of Gly and AT4. (a) Wide range $\left(400-4000 \mathrm{~cm}^{-1}\right)$, (b) narrow range $\left(1000-1800 \mathrm{~cm}^{-1}\right)$. 


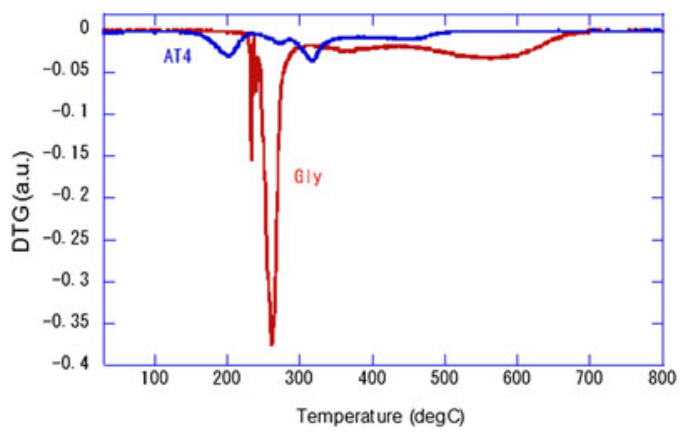

FIG. 5. Differential thermogravimetric (DTG) profiles of Gly and AT4.

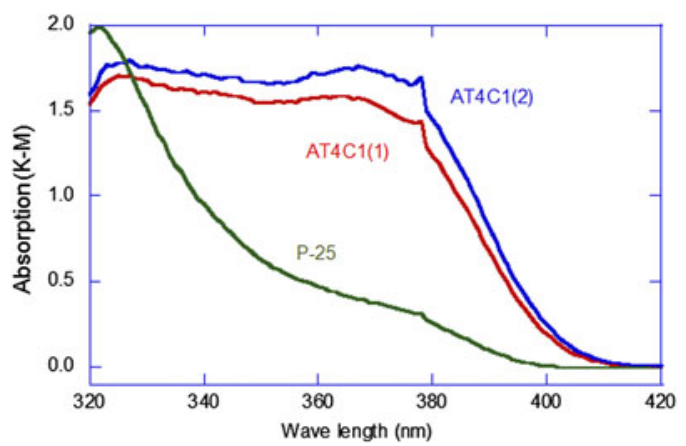

FIG. 6. Diffuse reflectance spectra of P-25 and AT4 after annealing at $500{ }^{\circ} \mathrm{C}$ in air AT4C1(1) and (2) are the samples from different P-25 lots.

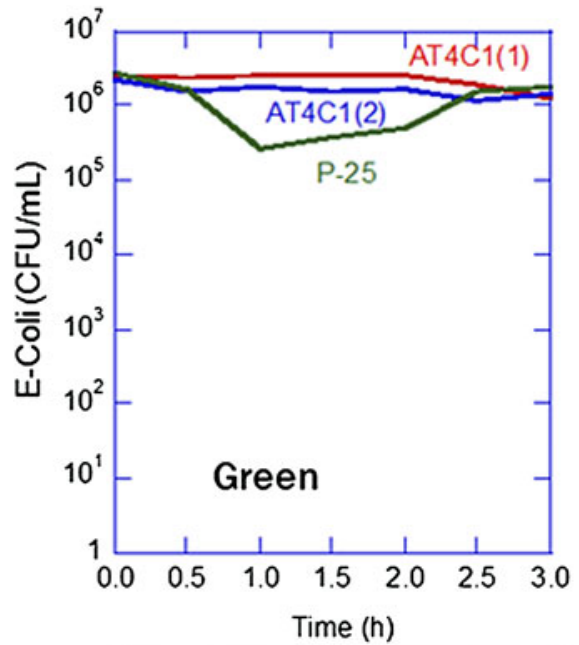

(a)

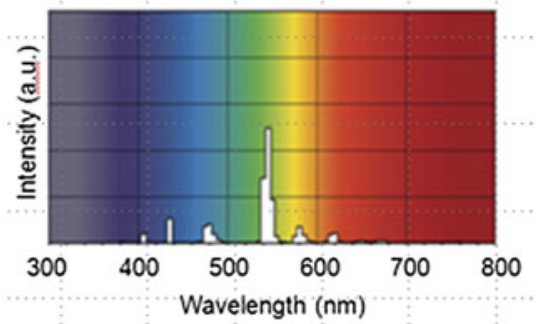

(a)

(b)
In contrast, Fig. 7(b) shows significant photocatalytic activity for the AT4C samples under blue light irradiation, which would correspond to an indoor-type illumination. The parent $\mathrm{P}-25$ powder shows no activity while the two attrition-milled powders show significant activity with all bacteria being destroyed after exposure for $2 \mathrm{~h}$. This corresponds well to the improved absorption spectra of the attrition-milled powders in the blue regime, shown in Fig. 6.

\section{DISCUSSION}

\section{A. Surface chemical interactions by attrition milling and subsequent annealing}

Vargova et al. studied glycine-metal complex formation in detail by means of infrared spectroscopy. ${ }^{27}$ The disappearance of the absorption bands below $800 \mathrm{~cm}^{-1}$, i.e., those due to $\mathrm{PVdF}$, e.g., of $\mathrm{COO}^{-}$scissoring, ${ }^{27}$ implies partial decomposition of $\mathrm{PVdF}$ during attrition milling. We also observed the blue shift of the absorption peaks for the absorption bands between 1300 and $1500 \mathrm{~cm}^{-1}$, as shown in Fig. 3(b). Valgova et al. attributed the blue shift of the $\mathrm{COO}^{-}$stretching IR absorption band to the connection of the carboxylate anion to the coordination surroundings of the metallic ion, i.e., entrance into the ligand field of the central metallic ion. ${ }^{27}$ Although the metallic species they studied was $\mathrm{Zn}$, similarity to the present study in this respect is clear.

Based on the detailed XPS studies, Wilson et al. confirmed the most probable conformation of Gly that
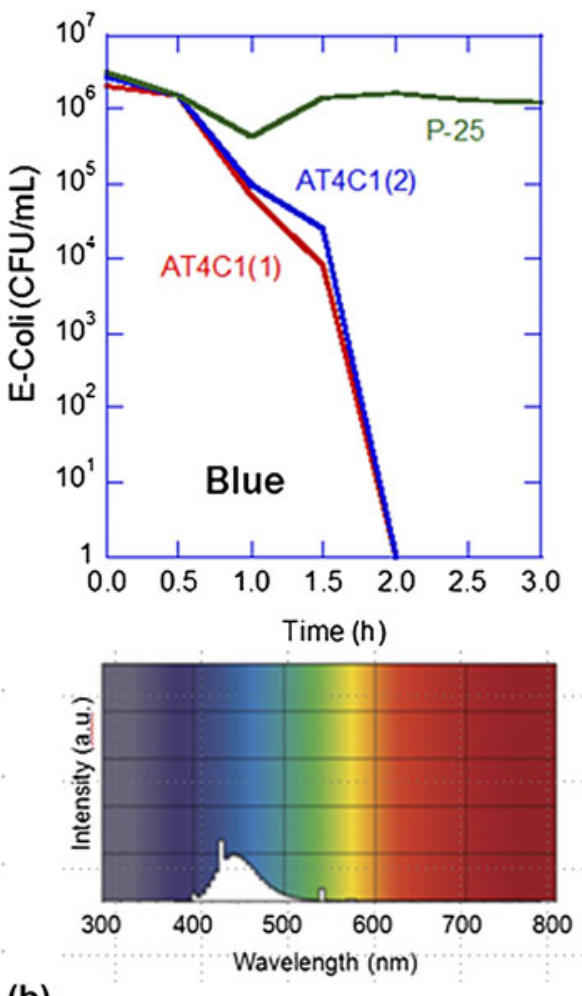

FIG. 7. Antibacterial photocatalytic activity under green and blue lights of P-25 and AT4 after annealing at $500{ }^{\circ} \mathrm{C}$ in air. 
adsorbed onto $\mathrm{TiO}_{2}(011)$ to be a bidentate bridging. ${ }^{30}$ They concluded that the oxygen atoms in the carboxylate are entering into the ligand field of $\mathrm{Ti}^{4+}$. As shown in Fig. 4(b), the N1s peak of the complex, AT4C1, could be separated into two, i.e., those that peaked at $399.8 \mathrm{eV}$ and the others that peaked at $401.5 \mathrm{eV}$. This strongly supports the complex formation between Gly and titania, as Polleux et al. also observed very similar N1s peaks from a titaniabased complex, prepared via a solution route with 2-amino2-hydroxymethyl-1,3-propanediol (trizma), as an organic counterpart. ${ }^{31}$

We also checked that N1s XPS signal was negligible in the pristine P-25, before and after heating to $500{ }^{\circ} \mathrm{C}$, so that it seems safe to conclude the second N1s peak at $399.8 \mathrm{eV}$ in AT4C1 or AT4C2 is ascribed so the nitrogen introduced from Gly via complex species mentioned above. As we observed the XPS spectra on sample AT4 after heating at $500{ }^{\circ} \mathrm{C}$, we did not recognize significant $\mathrm{N} 1 \mathrm{~s}$ signal. However, we clearly observed the visible light absorption in Fig. 6. These observations are compatibly explained by assuming the disproportionation of nitrogen species during heating. A fraction of nitrogen was depleted by the decomposition of the complex species formed on the surface of P25 nanoparticles, which was clearly picked up by XPS as N1s signal, due to the preferential capture of the near surface information by XPS. The other fraction, on the other hand, went into the lattice of titania. Only the latter fraction was able to contribute to the change in the electronic state enabling the catalytic activity. The latter fraction, however, is less sensitive to XPS. Since the amount of nitrogen play an important role on the catalytic activity, ${ }^{32,33}$ variation of nitrogen concentration by the present method should be examined in near future.

Detailed studies using thermogravimetric analyzer coupled with Fourier transform infrared (TG-FTIR) spectroscopy by Li et al. showed the decomposition product sequence of commercially available Gly as $\mathrm{H}_{2} \mathrm{O}$ and $\mathrm{NH}_{3}, \mathrm{CO}_{2}$, $\mathrm{CO}$, and isocyanic acid (HNCO). ${ }^{34}$ Although one-to-one correspondence of the observed differential thermogravimetric (DTG) peaks in the present study to these sequence is not possible at present, the DTG peak shift to the lower temperature side and increased separation of the peaks observed might imply the decomposition promotion due to the thermocatalytic action of the titania substrate and the complex formation. This is attributed to the specific binding of the molecular fractions, due to the specific adsorption configuration. ${ }^{30}$ From all these results, we suggest the scheme illustrated in Fig. 8 as a simplified process of formation of the complex between titania and Gly, and incorporation of nitrogen into titania.

\section{B. Photocatalytic activity}

The strong photocatalytic activity shown in Fig. 7(b) means that the present Gly-modified titania nanoparticles

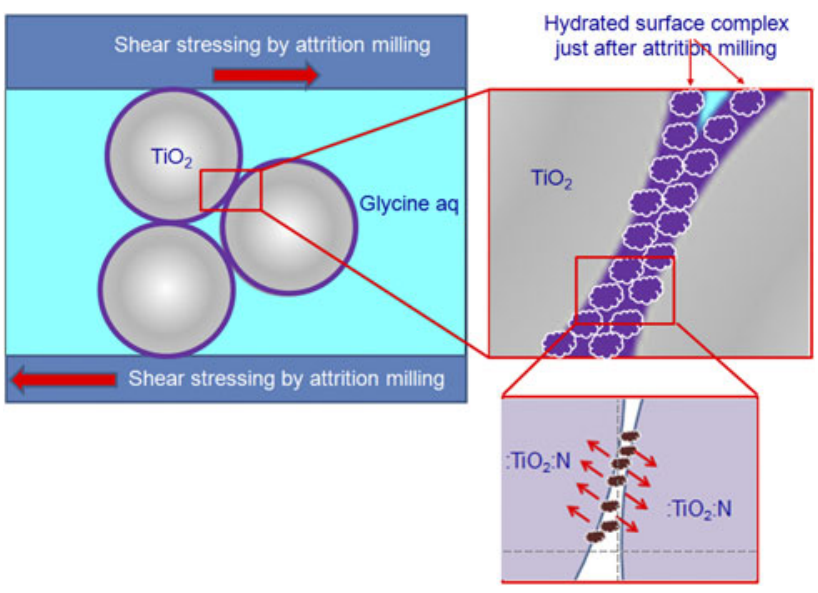

FIG. 8. A scheme of the reaction processes.

could be used for attack against bacteria within enclosed space under soft blue illumination. By referring the literature, ${ }^{35-40}$ these results suggest that the $>\mathrm{N}$-doping has created intermediate energy levels in the band gap, which allow the production of some type of oxidizing species. Because of the relatively low energy of these wave lengths, species such as oxygen singlet $\mathrm{O}_{2}{ }^{1}$ are expected rather than the hydroxyl radical, ${ }^{*} \mathrm{OH} .{ }^{11,41}$ For a better understanding of the detailed mechanisms with respect to the active species in the present antibacterial photocatalytic activity, we need further work.

\section{CONCLUSIONS}

Surface functionalization and modification of rheological properties of titania nanoparticles were achieved simultaneously when they were dispersed in a slightly acidic aqueous solution of Gly. Reduction of particle size with accompanying slight flocculation took place by attrition milling. The observed granulometrical, colloidal and chemical changes by attrition milling consistently indicate the formation of the Gly-derived complexes on the surface of titania. When the dispersion was dried and further calcined at $500{ }^{\circ} \mathrm{C}$ in air, nitrogen was incorporated into titania, judging from the color change to pale yellow, and the DRS in the visible region. The fired product, i.e., titania nanoparticles with partial anion exchange of oxygen with nitrogen, exhibited a high photocatalytic antibacterial activity by irradiation of blue light centered at around $440 \mathrm{~nm}$, as demonstrated using Escherichia coli (E-Coli) as a specimen of bacterial species. The present Gly-modified titania nanoparticles could, therefore, be used for the purpose of attack against bacteria within enclosed space attacking material under soft blue illumination.

\section{ACKNOWLEDGMENTS}

The authors thank Mr. Carlos Morais for his experimental assistance. V.L. acknowledges N. Xanthopoulos 
(EPFL-Interdisciplinary Center for Electron Microscopy) for performing XPS analyses.

\section{REFERENCES}

1. P. Bowen, H. Hofmann, M. Staiger, R. Steiger, P-A. Brugger, and K. Peternell: Colloidal processing of nanoceramic powders for porous ceramic film applications. Key Eng. Mater. 206-213, 1977 (2002).

2. P. Bowen and C. Carry: From powders to sintered pieces: Forming, transformations and sintering of nanostructured ceramic oxides. Powder Technol. 128, 248 (2002).

3. M. Staiger, P. Bowen, J. Ketterer, and J. Bohonek: Particle size distribution measurement and assessment of agglomeration of commercial nanosized ceramic particles. J. Dispersion Sci. Technol. 23, 619 (2002).

4. P. Bowen, C. Carry, D. Luxembourg, and H. Hofmann: Colloidal processing and sintering of nanosized transition aluminas. Powder Technol. 157, 100 (2005).

5. M.R. Hoffmann, S.T. Martin, W. Choi, and D.W. Bahnemann: Environmental application of semiconductor photocatalysis. Chem. Rev. 95, 69 (1995).

6. H. Tong, S. Ouyang, Y. Bi, N. Umezawa, M. Oshikiri, and J. Ye: Nanophotocatalytic materials: Possibilities and challenges. Adv. Mater. 24, 229 (2012).

7. T. Tachikawa, M. Fujitsuka, and T. Majima: Mechanistic insight into the $\mathrm{TiO}_{2}$ photocatalytic reactions: Design of new photocatalysts. J. Phys. Chem. C 111, 5259 (2007).

8. M.K. Lee, T.H. Shih, and C.M. Shih: Highly visible photocatalytic activity of fluorine- and nitrogen-codoped nanocrystalline anatase phase titanium oxide converted from ammonium oxotrifluorotitanate. IEEE Trans. Nanotechnol. 6, 316 (2007).

9. M.A. Henderson: A surface science perspective onTiO ${ }_{2}$ photocatalysis. Surf. Sci. Rep. 66, 185 (2011).

10. G. Liu, L. Wang, H.G. Yang, H.M. Cheng, and G.Q. Lu: Titaniabased photocatalysts - crystal growth, doping and heterostructuring. J. Mater. Chem. 20, 831 (2010).

11. Q. Xiang, J. Yu, and M. Jaroniec: Nitrogen- and sulfur-codoped $\mathrm{TiO}_{2}$ nanosheets with exposed $\{001\}$ facets: Synthesis, characterization and visible-light photocatalytic activity. Phys. Chem. Chem. Phys. 13, 4853 (2011)

12. J. Yu, W. Wang, B. Cheng, and B-L. Su: Enhancement of photocatalytic activity of mesoporous $\mathrm{TiO}_{2}$ powders by hydrothermal surface fluorination treatment. J. Phys. Chem. C 113, 6743 (2009).

13. S. Liu, J. Yu, and W. Wang: Effects of annealing on the microstructures and photoactivity of fluorinated $\mathrm{N}$-doped $\mathrm{TiO}_{2}$. Phys. Chem. Chem. Phys. 12, 12308 (2010).

14. S. Liu, J. Yu, and M. Jaroniec: Anatase $\mathrm{TiO}_{2}$ with dominant highenergy $\{001\}$ facets: Synthesis, properties, and applications. Chem. Mater. 23, 4085 (2011).

15. S. Livraghi, M.R. Chierotti, E. Giamello, G. Magnacca, M.C. Paganini, C. Cappelletti, and C.L. Bianchi: Nitrogen-doped titanium dioxide active in photocatalytic reactions with visible light: A multi-technique characterization of differently prepared materials. J. Phys. Chem. C 112, 17244 (2008).

16. G. Liu, X. Wang, Z. Chen, M.M. Cheng, and G.Q. Lu: The role of crystal phase in determining photocatalytic activity of nitrogen-doped $\mathrm{TiO}_{2}$. J. Colloid Interface Sci. 329, 331 (2009).

17. R. Rattanakam and S. Supothina: Visible-light-sensitive N-doped $\mathrm{TiO}_{2}$ photocatalysts prepared by a mechanochemical method: Effect of a nitrogen source. Res. Chem. Intermed. 35, 263 (2009).

18. K.T. Ranjit, E. Joselevich, and I. Willner: Enhanced photocatalytic degradation of $\pi$-donor organic compounds by $N, N^{\prime}$-dialkyl-4,4'bipyridinium-modified $\mathrm{TiO}_{2}$ particles. J. Photochem. Photobiol., A, 99, 85 (1996).
19. N. Watanabe, S. Horikoshi, H. Hidaka, and N. Serpone: On the recalcitrant nature of the triazinic ring species, cyanuric acid, to degradation in Fenton solutions and in UV-illuminated $\mathrm{TiO}_{2}$ (naked) and fluorinated $\mathrm{TiO}_{2}$ aqueous dispersions. J. Photochem. Photobiol., A 174, 229 (2005).

20. D. El Mekkawi and M.S.A. Abdel-Mottaleb: The interaction and photostability of some xanthenes and selected azo sensitizing dyes with $\mathrm{TiO}_{2}$ nanoparticles. Int. J. Photoenergy 7, 95 (2005).

21. M. Senna, V. Sepelak, J. Shi, B. Bauer, A. Feldhoff, V. Laporte, and K-D. Becker: Introduction of oxygen vacancies and fluorine into $\mathrm{TiO}_{2}$ nanoparticles by comilling with PTFE. J. Solid State Chem. 187, 51 (2012).

22. M.H. Ahn, E.S. Cho, and S.J. Kwon: Effect of the duty ratio on the indium tin oxide (ITO) film deposited by in-line pulsed DC magnetron sputtering method for resistive touch panel. Appl. Surf. Sci. 258, 1242 (2011).

23. H. Liu, V. Avrutin, N. Izyumskaya, Ü. Özgür, and H. Morkoç: Transparent conducting oxides for electrode applications in lightemitting and -absorbing devices. Superlattices Microstruct. 48, 458 (2010).

24. K. Iwasa, T. Isobe, and M. Senna: Enhanced densification of ITO ceramics for sputter target through wet mechanochemical processing. Solid State Ionics 101-103, 71 (1997).

25. ISO Standard 20743: Evaluation of the Antibacterial Activity of Biocidal Products (International Organization for Standardization, Geneva, Switzerland, 2007).

26. R.J. Flatt and P. Bowen: Yodel: A yield stress model for suspensions. J. Am. Ceram. Soc. 89, 1244 (2006).

27. Z. Vargová, M. Almási, L. Arabuli, K. Györyová, V. Zelenák, and J. Kuchár: Utilization of IR spectral detailed analysis for coordination mode determination in novel $\mathrm{Zn}$-cyclen-amino acid complexes. Spectrochim. Acta A78, 788 (2011).

28. T. Rajh, L.X. Chen, K. Lukas, T. Liu, M.C. Thurnauer, and D.M. Tiede: Surface restructuring of nanoparticles: An efficient route for ligand-metal oxide crosstalk. J. Phys. Chem. B106, 10543 (2002).

29. Unpublished data, to appear.

30. J.N. Wilson, R.M. Dowler, and H. Idriss: Adsorption and reaction of glycine on the rutile $\mathrm{TiO}_{2}$ (011) single crystal surface. Surf. Sci. 605, 206 (2011).

31. J. Polleu, N. Pinna, M. Antonietti, C. Hess, U. Wild, R. Schlögl, and M. Niederberger: Ligand functionality as a versatile tool to control the assembly behavior of preformed titania nanocrystals. Chem. Eur. J. 11, 3541 (2005).

32. J. Yu, M. Zhoua, B. Chenga, and X. Zhaoa: Preparation, characterization and photocatalytic activity of in situ N, S-codoped $\mathrm{TiO}_{2}$ powders. J. Mol. Catal. A: Chem. 246, 176 (2006).

33. M. Zhou and J. Yu: Preparation and enhanced daylight-induced photocatalytic activity of $\mathrm{C}, \mathrm{N}, \mathrm{S}$-tridoped titanium dioxide powders. J. Hazard. Mater. 152, 1229 (2008).

34. J. Li, Z. Wang, X. Yang, L. Hu, Y. Liu, and C. Wang: Evaluate the pyrolysis pathway of glycine and glycylglycine by TG-FTIR J. Anal. Appl. Pyrolysis 80, 247 (2007).

35. D. Gumy, P. Bowen, C. Morais, C. Pulgarin, S. Giraldo, R. Haijdu, and J. Kiwi: Catalytic activity of commercial of $\mathrm{TiO}_{2}$ powders for the abatement of the bacteria (E coli) under solar simulated light: Influence of the isoelectric point. Appl. Catal., B 63, 76 (2006),

36. J.A. Rengifo-Herrera, E. Mielczarski, J. Mielczarski, N.C. Castillo, J. Kiwi, and C. Pulgarin: Escherichia coli inactivation by N, S codoped commercial $\mathrm{TiO}_{2}$ powders under UV and visible light. Appl. Catal., B 84, 448 (2008).

37. J.A. Rengifo-Herrera, K. Pierzchała, A. Sienkiewicz, L. Forro, J. Kiwi, and C. Pulgarin: Abatement of organics and Escherichia coli by N, S codoped $\mathrm{TiO}_{2}$ under UV and visible light. Implications of the 
formation of singlet oxygen $\left({ }^{1} \mathrm{O}_{2}\right)$ under visible light. Appl. Catal., $B$ 88, 298 (2009).

38. J.A. Rengifo-Herrera, J. Kiwi, and C. Pulgarin: N, S codoped and N-doped Degussa P-25 powders with visible light response prepared by mechanical mixing of thiourea and urea. Reactivity towards E. coli inactivation and phenol oxidation. J. Photochem. Photobiol., A 205, 109 (2009).

39. J.A. Rengifo-Herrera and C. Pulgarin: Photocatalytic activity of $\mathrm{N}, \mathrm{S}$ codoped and $\mathrm{N}$-doped commercial anatase $\mathrm{TiO}_{2}$ powders towards phenol oxidation and E. coli inactivation under simulated solar light irradiation. Sol. Energy 84, 37 (2010).

40. J.A. Rengifo-Herrera, K. Pierzchała, A. Sienkiewicz, L. Forro, J. Kiwi, J.E. Moser, and C. Pulgarin: Synthesis, characterization, and photocatalytic activities of nanoparticulate $\mathrm{N}$, S-codoped $\mathrm{TiO}_{2}$ having different surface-to-volume ratios. J. Phys. Chem. C 114, 2717 (2010).

41. Q. Xiang, J. Yu, and P.K. Wong: Quantitative characterization of hydroxyl radicals produced by various photocatalysts. J. Colloid Interface Sci. 357, 163 (2011). 